\title{
Sibling Effects on Adult Earnings Among Poor and Wealthy Children Evidence from Sweden
}

\author{
Frida $\operatorname{Skog}^{1}$ (D)
}

Accepted: 6 May 2018 /Published online: 26 May 2018

(C) The Author(s) 2018

\begin{abstract}
While previous research in general observes adverse effects of siblings on children, less is known about the ways in which material circumstances condition these effects. Using propensity score matching on longitudinal data, this study estimates the effects of being an only child, being born first, and having a large sibling group on adult earnings. Estimates are made for poor and wealthy children respectively in order to examine whether effects occur for both groups. The results show that being an only child, or having a large sibling group, impacts negatively on adult earnings among poor children. Having one younger sibling furthermore has a positive effect on adult earnings among poor children. No corresponding effects were observed for wealthy children. The results indicate that sibling effects are not linear and that they are dependent on family resources.
\end{abstract}

Keywords Siblings $\cdot$ Sibling effects $\cdot$ Adult earnings $\cdot$ Sweden $\cdot$ Propensity score matching

\section{Introduction}

The literature dealing with sibling effects is extensive. In previous investigations, siblings have primarily been treated as 'diluters', rather than contributors, of resources (see for example Downey 1995; Steelman et al. 2002; Jæger 2009). But there are exceptions, in research treating siblings as possible providers of resources - that potentially can be transformed into financial capital (Coleman 1988) - and thus potentially impacting positively on children. More recent research has begun to analyse siblings as resources in themselves (Downey and Condron 2004; Downey et al. 2015; Yucel and Downey 2015; Yucel and Yuan 2015). Siblings may be competitors, but they may also be

Frida Skog

frida.skog@miun.se

1 Social Sciences Department, Mid Sweden university, Östersund, Sweden 
companions and role models during childhood, as well as sources of support during adult life. To have siblings may, in other words, influence a child's life in different ways.

After decades of research on siblings it is somewhat surprising to find that scholars have largely left questions regarding the socioeconomic conditioning of sibling effects empirically unexplored. While sibling effects have been observed for the general population little is known about the ways in which material circumstances in childhood condition these effects. Investigating sibling effects across entire populations assumes that the effects are universal in character and magnitude for most individuals, regardless of their positions. Empirical heterogeneities and variations in sibling effects - linked to, for instance, class differences - may thus be cancelled out by aggregation. Unpacking the mechanisms through which siblings' impact on the lives of children is crucial for understanding whether siblings are factors of protection or of risk. By analysing outcomes for children that should be more susceptible to sibling effects, as well as for children growing up in more protective environments, this paper aims to understand the interaction effects through which siblings function as competitors or social support.

This paper investigates if economic circumstances in childhood condition the effects of siblings on adult earnings. By investigating the long-term effects of siblings on adult earnings among poor and wealthy children respectively, the paper aims to provide a better understanding of the mechanisms through which siblings may function as competitors or resources for children. I analyse sibling effects in two samples of polarised household earnings distributions, the richest and the poorest, in order to examine whether effects occur at the vulnerable end, or at the protected end, or equally at both. The sibling variable is not a linear indicator (i.e. number of siblings) in the analysis, but constructed rather to capture weather siblings constitute social support or dilutes resources for children. These constructs are only child, birth order and number of siblings. Although the literature regarding sibling effects is extensive, few studies have investigated the impact on earnings (Björklund et al. 2009; Åslund and Grönqvist 2010; Lampi and Nordblom 2012). The model I employ is straightforward and the goal is modest; to uncover differences in sibling effects on adult earnings between rich and poor children. Being rich and being poor can be defined and measured in different ways. Most established measures are relative, some to the median income and others to the total income distribution. In order to discriminate poor families from rich families analytically, I select the bottom 10th and the top 90th earnings percentiles respectively to represent the two groups. This means that poverty is defined as the poorest $10 \%$ of the income distribution and wealth is defined as the richest $10 \%$ of the income distribution.

The study is based on Swedish administrative data and includes all firstborns born in Sweden in 1971, 1972, 1973, and 1974. I follow this population for 35 years. The sample is of good quality with precise links between family members, and detailed information on a range of family background characteristics and adult earnings. The statistical method used is propensity score matching which targets a causal parameter, an average causal effect, defined in the potential outcomes framework (Rubin 1974; Holland 1986; Imbens 2015).

\section{Supporters or Diluters?}

The concept of family social capital generally refers to the ties between parents and children, parent-child interactions, and the social investments - in terms of for example 
time and attention - that parents make in the child (Coleman 1988; Israel et al. 2001; Ferguson 2006; Putnam 2000; Parcel et al. 2010). However, as research has identified the importance of networks and support mechanisms not linked specifically to the parents (Lu 2009), conceptualising siblings also as resources for children has become more common (Downey et al. 2015; Yucel and Downey 2015). Studies exploring the protective effects of siblings have challenged the long held belief that siblings depress children's development by increasing competition for parental resources. Focusing on social and interpersonal skill development, Downey and Condron (2004) find that the often-replicated negative association between number of siblings and cognitive outcomes (observed by for example Zajonc 1976, 2001) does not extend to social skills, and observe that children with at least one sibling have better social and interpersonal skills than only children do. Baydar et al. (1997) present evidence suggesting that the birth of a sibling may improve peer relations for children, and Zajonc (1976, 2001) similarly suggests that siblings may affect each other's cognitive abilities positively, as well as motivate and support each other's schoolwork. All these effects may extend to occupational and monetary attainments later in life.

Conger et al. (2009), Gass et al. (2007), Kempton et al. (1991), and Sandler (1980) report that the presence of siblings might be a source of social support, buffering children from stress and social risk factors (see also Herrick and Piccus 2005). Milevsky (2005) shows that sibling support can compensate when support from other sources - such as friends and parents - is limited. Downey and Condron (2004) suggest that the sibling relationship might provide emotional and social support that counteracts adverse effects of inadequate parenting. If negative resources - such as abuse, violence, and negligence - are also diluted as siblings are introduced, then siblings would protect children from risks associated with these circumstances too. Sandefur et al. (2006) find no indications of siblings being a source of social support. However, as most studies focus on families with no explicit, or no known, social problems, they contribute little to the knowledge about the effects of siblings in families with, for instance, economic difficulties.

As only children are not exposed to sibling competition, and possibly receives higher levels of parental supervision, they have been labelled "little emperors" (Cameron et al. 2013; Wang and Fong 2009), or "brats" (Crowell and Hsieh 1995). It is commonly agreed that children growing up with siblings have experiences that are differently characterised from those that do not have siblings. Lau and Li (2011), examining children's well-being in China, argue that only children are deprived of opportunities to learn social skills through interaction with siblings, and that children who lack emotional and social support at home need more support from social networks external to the family. They also find that children with highly educated and well-paid parents have closer interactions with both parents and peers than children from more disadvantaged circumstances. Yucel and Downey (2015), Yucel and Yuan (2015), and Downey et al. (2015) furthermore suggest that social skills that facilitate peer relations is something that siblings acquire from each other.

In a large number of empirical investigations, siblings have been conceptualised primarily as resource diluters rather than resources (see Blau and Duncan 1967; Blake 1981; Downey 1995, 2001; Powell and Steelman 1990; Zajonc and Markus 1975, Conley 2001; and Steelman et al. 2002 for a review). This literature has observed negative associations between the number of siblings and child outcomes such as educational performance and cognitive attainment. A general assumption of the often applied resource 
dilution model (Blake 1981) is that parental resources such as capital, social and emotional support, and time spent with the child, are diluted by each additional sibling. The model posits that the negative effects of siblings should be particularly noticeable in poorer families, where resources are scarce to begin with (Steelman et al. 2002). In socioeconomic contexts in which the majority of families are able to provide sufficiently for their needs, additional siblings may dilute the resources in a noticeable way only among those who are very poor (Phillips 1999; Ponczek and Souza 2012).

The assumption that siblings provide social support as well as opportunities for fostering social competences is complicated by empirical findings showing that firstborns seem to perform better than only children, secondborns, and thirdborns, and so on (Zajonc and Markus 1975). From these findings an additional theoretical perspective, the firstborn advantage, has emerged. However, if sibling gains are asymmetrically allocated, the arguments presented above regarding social support and social skills suggest that younger siblings should be performing better than the older ones. In part, the firstborn advantage has been explained by better social training received by firstborns from tutoring their younger siblings. In part, it has also been explained by the resource dilution model since this assumes that the oldest child receives more resources from the parents than the following siblings do (Conley and Glauber 2006).

\section{Economic Circumstances in Childhood as a Conditional Factor for Sibling Effects}

While the question of how these mechanisms are conditioned by different economic circumstances has been touched upon by the two theoretical models described above, it has largely been bracketed in empirical studies of sibling effects. In order to investigate this question further, we need to consider the ways in which economic resources can be thought to impact on sibling effects. The two different pathways through which siblings are assumed to influence the life chances of children both suggest that the family environment, and family resources, largely mediate such effects. Family income and wealth are distinctive among the resources available to a child, but so are relational resources too - such as parental attention and social networks. The question is not whether sibling effects are stronger among poor or affluent children, but rather - given the life chance differences they are facing - how we should understand and conceptualise the effects of siblings in relation to the two groups?

Numerous studies on the effects of poverty on children - including effects caused by parental stress and insufficient parenting - underscore the importance of social support for vulnerable children (see Cohen and Wills 1985; Evans 2004; Guo and Harris 2000; Lugo-Gil and Tamis-LeMonda 2008; Mayer 1997; Seccombe 2000; White and Rogers 2000; Conger et al. 1994; Emery and Laumann-Billings 1998; Magnuson and Duncan 2002; Brooks-Gunn and Duncan 1997; Leventhal and Brooks-Gunn 2000; Dahl and Lochner 2012). While these studies have explored parent-child relations, and sources of social support external to the family, empirical analyses of the importance of sibling relations for children living in poverty have not yet been provided.

While limited access to material resources is a defining feature of poverty, studies focusing on the experiences of poor children have emphasised the relational dimensions 
of poverty, showing how negative consequences of poverty are experienced in social relations and social activities (Ridge 2002, 2011). Poverty, in other words, constrains participation for children in both social and material regards. Poor children are more often than their more advantaged fellows excluded from extra-curricular school activities, and also from everyday activities where requirements for participation are sometimes substantial. Lack of friendship, fear of bullying, and fear of exclusion, characterise the lives of poor children, as do experiences of weekends and holidays as periods of loneliness and isolation. Against this backdrop it is difficult to theorise poor children without siblings in terms of 'little emperors'.

Considering the specific challenges that poor children are facing, siblings may be protective factors compensating for adversities and loneliness. For children growing up in a context characterised by stress and vulnerability, siblings may mitigate parental shortcomings and contribute positively to a sense of safety and continuity. Poor children without siblings may thus be even more vulnerable and isolated. The emotional and social resources gained from siblings would also be especially important for children with parents who provide them with negative resources. Poor parenting may also result in poor sibling relations, and siblings lacking the abilities to provide each other with social support. Poor children may also be required to take on adult responsibilities early on in life, and assume adult roles in their family networks (Roy et al. 2014), as described by Burton (2007) in terms of adultification and parentification. Adultification and parentification are understood to produce both resources and strains for children. While experiences of taking on adult roles and responsibilities may be stressful and disrupt the normal development, they may also contribute to processes of learning and maturing, which may impact positively on adult attainment. These arguments thus support conceptualising siblings also as supporters and not only as diluters. In accordance with the siblings-as-supporters model, we should hypothesise that being an only child is negative for children in poverty. Conversely, we should hypothesise that being an only child is positive for poor children in accordance the resource dilution model.

Even though the suggested mechanisms between siblings and child outcomes are likely to be contingent on family resources, virtually no attention has been given so far to sibling relationships in wealthy families either. While poverty affects the child negatively through several interrelated factors as discussed above, wealth should accordingly affect children's development positively through the same set of factors, albeit inversed. Besides having access to more material resources, it can be assumed that rich children experience less parental stress, more sufficient parenting, more social support from parents, and have access to more extended social networks, than poor children do. While poverty is known to increase risks for low-quality parenting through, for example, distress and marital discord caused by lack of resources (Slack et al. 2004), parenting in affluence is often seen as unproblematic. The notion of 'little emperors' implies affluence and high levels of supervision, and is thus easily applied to rich children without siblings. Since the home environment for wealthy children should not be characterised by vulnerability and stress, their siblings should not be required to provide them with protective support.

Research on rich children has nevertheless been able to identify adjustment problems, lack of parental supervision due to career priorities, issues relating to depression, anxiety, substance use, achievement pressures, as well as isolation from adults and 
erosion of family time (Luthar and Sexton 2004) and adultification (Luthar 2003). While loneliness and isolation may be characterising features of poor children's lives, achievement pressures, overscheduling, and stress, characterise the everyday lives of rich children (Luthar 2003; Luthar and Becker 2002; Luthar and Latendresse 2005). These circumstances have been linked to problems such as insomnia, headaches, and depression. The hectic lifestyles of the wealthy have been suggested to destabilise family life, and decrease the quality of family relations. These findings actually make us question if only children in wealthy families are as spoiled as popular belief suggests.

It is not entirely clear how experiences such as these intersect with the effects of having siblings. A sibling could be of great importance in a situation where parents have limited family time, but a sibling suffering from psychological stress could also be a burden, and especially so if the child takes on a supervisory role for the sibling. Negative circumstances such as these are not necessarily exclusive to the affluent. When it comes to health and stress, social status has been shown to be of importance, i.e. health problems affect people on the bottom more than those on the top since psychosocial and health outcomes are contingent on material conditions (Marmot and Wilkinson 2006). Parental absence and negative sibling relations, and negative sibling resources, may characterise also the lives of poor children. Affluent children may also be hypothesised to have larger social networks, due to more extracurricular activities. It is thus plausible that the negative consequences, and stigma, of being an only child do not affect wealthy children as strongly. Furthermore, if siblings provide children with social capital and social support, they should be more important for children living in poverty than for wealthy children. If siblings are social resources, they may be of importance in both ends of the income spectra, but the quality of the sibling network is likely to be contingent on status and material resources. Assuming that wealthy children are less likely to suffer from resource dilution, but may experience social support needs, we thus hypothesise that being an only child has limited, or slightly negative, impact on their adult life chances.

\subsection{Birth Order Effects}

Whether financial constraints impact on birth order effects or not is still an open question, and different patterns have been observed (Kantarevic and Mechoulan 2006; De Haan et al. 2014). The firstborn advantage should be more significant for poor children than for rich children, given that the resource hypothesis is valid (Conley and Glauber 2008) and that firstborns have advantages in accessing parental resources compared to younger siblings. Using poverty as a conditional factor however complicates the other assumption of the firstborn advantage; that tutoring younger siblings produces benefits for firstborns. Younger siblings may benefit more from older siblings in a context of poverty, and particularly so if older siblings are able to protect the younger from harms inflicted by lacking resources, and social exclusion. The firstborn advantage should also be of lesser importance among wealthy siblings since their parents should be able to provide sufficiently for subsequent siblings as well.

The conceptual model of adultification and parentification both supports and complicates this assumption. It is intertwined with birth order in so far that the oldest child in the family is the one being exposed to adult stress and responsibilities and even taking on a parental role for younger siblings. Thus, the youngest child could receive 
important resources from the older siblings, who also acts as a buffer between inadequate parents and younger siblings. Being an adultified or parentified child has been hypothesized to intervene with a healthy development and derive a child of important childhood experiences. At the same time, adultification may also provide a child with important abilities, such as responsibility, social awareness, and leadership skills. Burton (2007) shows that these effects may be dependent on the support the adultified child gets from either parents or school. A parent with little material resources may still assist the child in interpreting the acquired abilities and the difficult circumstances in ways that will give the child a sense of meaning. With this in mind, it could be hypothesised that having an older sibling is positive for poor children. On the other hand, we could also hypothesise that being the firstborn in a poor family may provide a child with important abilities under the right circumstances, for example if the burdens of care are not too difficult to handle and if the child is able to make sense of the situation. For wealthy children it could be assumed that the firstborn advantage is of limited significance, due to resource affluence, but that older siblings may provide social support if this is something that is not readily available from parents.

With the resource dilution theory in mind, dilution of pre-natal parental resources and investments - including maternal behaviours and circumstances during pregnancy should be more pronounced for poor children (Aizer et al. 2016), and among secondborns, and conversely less important for the wealthy. From an economic point of view, it is reasonable to think that poor parents by necessity invest more in their firstborn child, and that affluent parents are able to invest equally - or in accordance with individual needs - in all of their children.

It can be expected that birth order is of importance for children in families with strained resources. From a resource dilution perspective, the firstborn advantage is hypothesised to be more pronounced for poor children due to the inability of parents to compensate children of higher birth order. But, following the assumption that siblings provide social support, older siblings should be more beneficial than younger siblings.

\subsection{Number of Siblings}

When it comes to the number of siblings, a more self-evident hypothesis emerges from the theoretical framework described above. A key assumption underlying this analysis is that resource competition should be less pronounced among wealthier groups since rich parents should be able to invest large amounts of resources in their children. The negative effects of having a large number of siblings should be larger in poor families, where resources are scarce to begin with and children growing up in poverty could be hypothesised to experience even higher sibling costs than those that have been observed for children in general. As mentioned previously, the quality of the sibling network could be contingent on material resources so that sibling relationships are of poorer quality in poor families than in affluent families. Poor siblings could be even stronger resources diluters than wealthy siblings. Wealthy children can be assumed to be less affected by sibling competition for resources, and sibling relationships can also be assumed to be of higher quality in this group. I therefore hypothesize no significant, or possibly a positive, effect of a large sibling group for wealthy children. 


\section{Data}

Using Swedish administrative data, my initial sample included every individual in four Swedish birth cohorts (1971, 1972, 1973, and 1974) comprising 390,070 individuals. The data contains information on all Swedish residents on a wide range of socioeconomic variables. To attain information on childhood circumstances, it is possible to link individuals to information on their parents from censuses made with five and ten-year intervals (from 1970, 1975, 1980, and 1990). In order to discriminate poor families from rich families analytically, I select the bottom 10th and the top 90th earnings percentiles respectively to represent the two groups. Each sample consequently contained 39,007 individuals. I have access to earnings for both the father and the mother. The total family earnings were calculated as the sum of the earnings of both parents, if they resided together. If the mother was registered as single in a census, the earnings of the father were excluded for the period represented by that census. Individuals with missing background values were discarded from the samples. All estimations presented in the article were made for these two samples separately. The outcome variable Adult earnings is the logarithm of the earnings variable measured when the individuals in the sample are between 37 and 40 years old - the most recent year of data observations available. The reason for taking the logarithmic earnings variable is to account for the relative value of money in the two different samples. The same amount of money may not mean the same thing for individuals from different ends of the earnings distribution. In order to minimise the effect of temporary earnings variations, the mean annual log earnings for 2008, 2009, and 2010 was calculated.

\subsection{Only Child, Birth Order and Number of Siblings}

While previous research commonly assumes an inverted linear relationship between the number of siblings and outcomes, I conceptualise siblings also as potential sources of support and resources. With this in mind, I argue that an examination of the presence of siblings, or the presence of older siblings, captures relational aspects of siblinghood in a better way than a continuous variable would do. As siblings can be theorised as many different things - having no siblings, having younger siblings, and being part of a large sibling group can all be assumed to affect a child in different ways - I construct groups for comparison using dichotomous indicators, based on the theoretical arguments presented above regarding siblings-as-resources and siblings-as-competitors. Different sibling positions are defined here theoretically as causing different outcomes, contributing independently to effects (see also Zajonc and Sulloway 2007). The indicators - or rather 'treatments', within the methodological framework employed here - used for analysis are only child, birth order and number of siblings.

In the analysis presented here, the treatments of being an only child, a firstborn child, and members of a large sibling group are compared to their respective 'controls'; siblings, lastborns, and members of a small sibling group. The first treatment is to be an only child. This variable has two values, either you have siblings (0), or you do not (1). The samples are restricted to firstborn children in order to isolate the suggested mechanism from the possible other mechanism of birth order. For the same reasons, the samples are furthermore restricted also with respect to the number of siblings. Thus, the selected children are firstborns who did, or did not, experience the birth of one, and 
only one, additional sibling. Secondly, the birth order variable defines a person as either being firstborn (1) or lastborn (0). The samples for this treatment are also restricted to children with no more than one sibling in order to isolate the mechanism from number of siblings. This means that we compare firstborn children to secondborn children who both have one sibling only. Third, children having more than two siblings are here defined as coming from a large sibling group (1) and they are compared to children with two siblings or less (0). Also here, the two samples consist of firstborn children only.

\subsection{Covariates}

Included in the analysis is a set of variables capturing individual and parental characteristics and circumstances in childhood. All variables included are assumed to impact both on sibling configuration and adult earnings. The included covariates are child's gender, mother's year of birth, father's year of birth, mother's earnings in 1975, father's earnings in 1975, mother's origin, father's origin, mother's education, and finally father's education. The reason for observing parental earnings in 1975, and not 1970, is because a large percentage of the parents were young and still in education in 1970. Parental birth year and parental earnings are continuous variables. The variables representing parental origin are dichotomous and distinguishes between Western (Northern, Central and Southern European, and Anglo-Saxon countries) origin on the one hand, and the rest of the world on the other. This is because Western immigrants are assumed to have similar labour market attachments to those of native Swedes. The education variables are also dichotomous, and distinguishes between those with up to secondary education on the hand, and tertiary education on the other.

\section{Method}

I employ a propensity score matching technique, conducting a counterfactual comparison of individuals that are as similar to the treated individuals as possible. Propensity score matching targets a causal parameter, defined in the potential outcomes framework (Rubin 1974; Holland 1986), and is less dependent on model assumptions than, for example, regressions are. For each individual there are two potential outcomes, Y0 denotes the outcome under no treatment and Y1 denotes the outcome under treatment. The causal effect of the treatment is defined as the difference between these potential outcomes (Y1-Y0). Instead of matching individuals on the covariates directly, i. e.; comparing individuals with the same values on the covariates, the propensity score is used to summarise the covariates and is denoted by $\mathrm{X}$. The propensity score is denoted by $\mathrm{e}(\mathrm{X})$, and defined as $\mathrm{e}(\mathrm{X})=\mathrm{P}(T=1 \mid \mathrm{X})$. The propensity score is produced on fitted probabilities from a regression, $\left(\mathrm{e}(\mathrm{X})=\left(1+\exp .\left(\mathrm{X}^{\prime} \beta\right)\right)\right.$, where $\beta$ is a vector of unknown parameters), used to predict sibling constellation, or treatment status, on baseline characteristics, i.e. covariates. Since the purpose of propensity score matching is to balance the covariates - rather than predicting the probability for an individual to end up in a particular sibling constellation - we are only interested in the parameter estimates from the regression if they show significant associations with the treatment variable. 
Given the conditions provided by the observed covariates, the propensity score is the probability for an individual to be placed under treatment, i.e., being an only child, a firstborn child or a member of a large sibling group. While there may be selection into treatment, within each propensity score, treated and untreated individuals have the same covariate distribution.

The propensity score is used for matching treated with controls. Accordingly, for each sample we specify three regression models, one for each treatment. For all baseline models, the included covariates are child's gender, mother's year of birth, father's year of birth, mother's earnings in 1975, father's earnings in 1975, mother's origin, father's origin, mother's education, and finally father's education. In propensity score matching, the validity of estimates is dependent primarily on the matching balance, and by improving the covariate balance we reduce model dependency. All baseline family background variables have been checked for balance, not just the ones included in the final logit models. The parameter of interest in this analysis is the causal effect of the defined treatments, and the matching estimator used is the Average Treatment Effect (ATE), E[Y1-Y0]. The estimator imputes the unobserved potential outcome for each individual with the outcome of an individual from the opposite treatment group on the basis of the propensity score. Matching is performed by replacement, with a fixed number of matches for each individual. Controls similar to the treated may be used several times for matching (Abadie and Imbens 2006).

Underlying all analyses here is the assumption that the covariate distributions for the treated and controls are overlapping, $0<\mathrm{P}(T=1 \mid \mathrm{X})<1$. Histograms plotting the overlap of the propensity scores for each treatment in both samples show that the overlap assumption is fulfilled (see Appendix, Figs. 1, 2, 3, 4, 5, and 6). The analyses also rely on the assumption that all confounding variables are observed, (Y1,Y0) $\perp \mathrm{T}$ | X. These two assumptions are referred to as "strong ignorability" (Rosenbaum and Rubin 1983). To assess the possible impact of an unobserved variable, a statistical test is performed; Rosenbaum bounds (Rosenbaum 2004). Rosenbaum bounds estimate how strong the impact of an unobserved variable needs to be, for the results of the analysis to change, by computing upper bounds on the inference. In the Rosenbaum methodology, a function, Gamma $(\Gamma)$, denotes the odds of belonging to a specific sibling constellation and the bounds represent inference quantities, or changes in a $p$-value for the hypothesis of no effect. All statistical analyses presented in this paper were performed using the software $R$, version 3.1.2 (R Core Team 2013). Estimations of the ATE were performed using the Matching package (as described in Sekhon 2011), and the sensitivity tests employed the psens function in the rbounds package (Keele 2014).

\section{Descriptive Statistics}

The unadjusted earnings distribution for both samples in all treatments is found in Table 1. Clearly, economic inequalities persist also in adulthood for these children. Those who grew up in affluent circumstances seem to be more fortunate in adulthood as regards earnings. The difference is around $\$ 11,000$ between our samples. For poor children, the outcomes for only children and siblings are very similar. Rich children with siblings however, have significantly higher earnings in adulthood than rich only 
children have. Looking at the outcome distribution for the second treatment - being born first - we see no significant differences among poor children. Among the rich however, we can see that firstborns have significantly higher adult earnings than secondborn children. As regards the third treatment - having a large sibling group Table 1 also shows significant earnings variations between treated and controls among the poor, with better outcomes for individuals having fewer siblings. For this treatment, there are no significant differences for wealthy children. Furthermore, it can be noted that the poor children have done pretty well, as their adult earnings are close to the mean of the analysed cohorts, while the wealthy children are well above the mean.

In Appendix, Tables 3, 4, 5, 6, 7, and 8, descriptive statistics and mean covariate differences, before and after matching, are presented for each treatment in both samples. The tables show that while differences in the covariate distribution can be observed before matching, matching generally improves the covariate balances. The differences in pre-treatment covariate distribution also suggest that different fertility mechanisms may be operating in our two samples. Parental socioeconomic characteristics may be linked to complex relational patterns, including parenting practices and fertility decisions. Poor children with no siblings are more often boys, they have older parents, their parents earn less, their mothers are more often of non-Western origin, and their fathers have higher education than poor children with siblings (see Table 3). For wealthy children (see Table 4), we observe circumstances that are very different. Here, there are more girls among only children than there are among siblings, and while the parents of wealthy only children are older, their mothers earn somewhat more, and both of their parents have lower education, than those of wealthy siblings. For the second treatment, being born first, the mother's earnings are higher when the first child is born in both samples (see Tables 5 and 6). But, while the earnings of poor children's fathers do not change much between the firstborn and the lastborn, it does increase for the wealthy fathers. For the last treatment, having a large sibling group, we see that there are more girls in the large sibling group among the poor, and that their parents are younger, their mothers earn more, and their fathers less, than those with fewer siblings (see Table 7). Among the wealthy, those with large sibling groups are also more often boys, their parents are

Table 1 Mean adult earnings by treatment groups and percentiles

\begin{tabular}{|c|c|c|c|c|c|c|}
\hline & \multicolumn{3}{|c|}{ Poor children } & \multicolumn{3}{|c|}{ Wealthy children } \\
\hline & mean & lower CI & upper CI & mean & lower CI & upper CI \\
\hline Only children & 29,298 & 28,237 & 30,354 & 41,893 & 40,633 & 43,201 \\
\hline Siblings & 30,559 & 30,060 & 31,077 & 44,932 & 44,167 & 45,676 \\
\hline Firstborns & 30,559 & 30,060 & 31,077 & 44,932 & 44,167 & 45,676 \\
\hline Secondborns & 29,251 & 28,691 & 29,852 & 41,467 & 40,843 & 42,142 \\
\hline Large sibling group & 27,601 & 26,868 & 28,366 & 44,598 & 42,199 & 47,044 \\
\hline Smaller sibling group & 30,491 & 30,090 & 30,920 & 44,602 & 43,979 & 45,263 \\
\hline
\end{tabular}

The mean adult earnings for the entire birth cohort is $\$ 30,351$. Note: Earnings indicated in US dollars, rounded off to the nearest dollar. 
older, their parents earn more, and their fathers more often have non-Western origin, than those having fewer siblings (see Table 8).

\section{Estimating the Propensity Score Model}

Odds ratios from the logit models are shown in Tables 9 and 10 (see Appendix). For poor children, the variables correlated to being an only child are mother's and father's year of birth, and mother's earnings and origin, as well as father's education. For wealthy children, the same treatment is associated with the year of birth and education of both parents, and father's earnings. Turning to the estimation of the propensity scores for birth order, we can see that the variables representing parental year of birth, the earnings of the mother, and the education of the father are all significantly associated with birth order for poor children. For wealthy children, the ages and earnings of both parents are significant, as well as the education and origin of the father. As regards causality, it is difficult to see how parental characteristics predict whether a child is born first or second. The modelling of the birth order treatment is therefore, strictly speaking, misspecified. While gender, origin, and to some extent education can be assumed not to change with this treatment, other family circumstances may very well change between births, for instance the labour market status of the mother, which may be weakened after the birth of the first child, and thus being more of a mediating factor, rather than a confounding variable. I argue however, that the model is useful here for the purpose of identifying differences in sibling effects between the rich and the poor. The third model furthermore shows that being a girl, parental year of birth and earnings, and the origin and education of the father, are significantly associated with poor children's propensity to have a large sibling group. For wealthy children, the significant variables are the education and age of both parents, as well as the father's earnings. These differences suggest that different mechanisms regulate fertility among the poor and the wealthy. Being an only child - or having many siblings - may very well be the result of different circumstances, and thus also be experienced differently, among poor and wealthy children respectively.

\section{Estimation of Average Causal Effects}

The results of the propensity score matching estimations are presented in Table 2 . The dependent variable is log adult earnings. The match estimator shows that being an only child affects earnings negatively for both poor and wealthy children, but the effect is statistically significant only for the poor children. The assumption that siblings should be important sources of resources for poor children therefore seems to hold. The effect seems to be contingent on economic resources, rather than of general character. It should perhaps be noted once again that individuals with no siblings are here compared to individuals with siblings, and that the analysis is not confounded by either birth order or sibship size, as only firstborns are included in the sample, and children from large sibling groups are excluded. In other words, these results thus support the siblings-asresources hypothesis, at least for children with limited access to resources, but it also suggests that a firstborn advantage may be in effect as well. 
Table 2 Average treatment effects. Log earnings

\begin{tabular}{|c|c|c|c|c|c|c|c|}
\hline \multicolumn{8}{|c|}{ Ate only child } \\
\hline Sample & Estimate & SE & CI lower & CI upper & P-value & (n) & Treated \\
\hline Poor & -0.24 & 0.07 & -0.37 & -0.11 & $<0.001$ & 7114 & 1748 \\
\hline Wealthy & -0.11 & 0.06 & -0.21 & 0.00 & 0.06 & 9582 & 2206 \\
\hline \multicolumn{8}{|c|}{ Ate firstborn child } \\
\hline Sample & Estimate & SE & CI lower & CI upper & $\mathrm{P}$-value & (n) & Treated \\
\hline Poor & 0.14 & 0.05 & 0.03 & 0.24 & 0.001 & 9315 & 5366 \\
\hline Wealthy & 0.06 & 0.03 & -0.01 & 0.13 & 0.08 & 16,819 & 7376 \\
\hline \multicolumn{8}{|c|}{ Ate large sibling group } \\
\hline Sample & Estimate & SE & CI lower & CI upper & P-value & (n) & Treated \\
\hline Poor & -0.35 & 0.06 & -0.47 & -0.23 & $<0.001$ & 11,116 & 2587 \\
\hline Wealthy & -0.16 & 0.09 & -0.34 & 0.02 & 0.80 & 11,212 & 878 \\
\hline
\end{tabular}

Proceeding to the second part of the analysis, birth order, the results show that the firstborns are advantaged in both groups, but also here the results are significant only for children growing up in poverty. This lends little support for the hypothesis that older siblings constitute an important resource for younger children growing up in poverty. To the contrary, the estimator shows that the firstborn child clearly is the most advantaged in the sibling group. This effect also seems to be dependent of economic resources, since it is not significant for wealthy siblings. Since all individuals in the sample have only one sibling, the estimated effect is not obscured by sibship size. Together with the first treatment estimator, showing adverse effects of being an only child for poor children, these observations lend strong support to the firstborn advantage hypothesis, since it is clearly the sibling born first who benefits from having a sibling.

As regards the third part of the analysis, number of siblings, the match estimator shows an adverse effect of growing up in a large sibling group for poor children. In the affluent population, I am not able to identify any such effect. My assumption that the effects of siblings, birth order and sibship size are contingent on economic resources - and that dilution would be more noticeable for children lacking economic resources - in other words seems to hold true. The assumption that siblings would be valuable for children in poverty also seems correct, but not exactly like it was hypothesised. The first part of the analysis clearly shows that it is beneficial for poor children to have siblings, but the social support hypothesis is complicated by the fact that it is better to have a younger sibling than to have an older sibling. If support is the mechanism, it is more intuitive to think that an older sibling would provide more support than a younger sibling would.

\subsection{Sensitivity Tests}

The Rosenbaum bounds sensitivity tests for the significant results (see Appendix, Table 11) show that they are indeed sensitive to bias. If $\Gamma$ changes the inference, even for values close to 1 , the results are interpreted as being sensitive to bias. $\Gamma$ is between 1.2 and 1.3 for all of the treatments, which means that a variable changing the odds of belonging to either treatment or control groups with 20 to $30 \%$ would change the 
conclusions of this study. However, while $\Gamma$ shows that an unobserved variable could potentially change the parameter estimates for the treatment effect, the possible impact of unobserved variables must be assessed theoretically. In order to be considered confounding, an unobserved variable must be thought of as potentially having a causal impact on both sibling constellation and adult earnings. The effects of the unobserved variable must furthermore be independent of the observed variables included in the model, in order for the odds ratios to be increased by it. Thus, we must be able to imagine a confounder, which is related to family relations but not directly correlated to the observed covariates, i.e. the socioeconomic characteristics of the family.

Even if household resources have been linked to parental behaviour and marital quality, sibling constellations may be confounded by other endogenous parental characteristics and family psychosocial factors such as experiences of pregnancy, child birth and periods of infancy, maternal and paternal health, and also factors belonging directly to child characteristics, such as personality, temperament and health. The family orientation of the parents, interest in their children, as well as their own family wellbeing, may also be of importance. The mental and physical health of parents are cofactors of poverty, as well as parental addiction. These factors are also related to poor mental and physical health in children. Family life in poor families is also likely to be less stable and more conflictual. However, if these important factors for child wellbeing are linked to the socio-economic standard of the parents and of the family as well as the outcome for the child, some of these effects should be captured by the models.

\section{Conclusions}

The results show, first, adverse effects of being an only child when compared to having one sibling for poor children only. This suggests that this effect is not of general character, and lends support to the social support hypothesis. The adverse consequences of being an only child may be specific to children lacking resources - perhaps related to experiences of social exclusion - and therefore possibly of different character among families with more resources. In relation to the theoretical arguments discussed above, it could be hypothesised that if children from the bottom end of the earnings spectrum are not gaining from being exempt from sibling competition, we may conclude that only children are not always the 'small emperors' they have been theorized to be.

These results, rather, suggest vulnerability among poor only children. The observed effect may be mediated by weaker social skills among only children, impacting negatively on interpersonal relations in childhood, adolescence and adulthood (Cameron et al. 2013). As discussed in relation to the sensitivity tests above, the effect may be confounded by parental traits, morbidity in the family, and features of the child. Only children may in other words have become only children because of circumstances that impact negatively also on their adult earnings. If this is true, these results suggest that a younger sibling could actually be beneficial for these children. The selection into, and the status of being, an only child may be of different character among the affluent families. Affluent children without siblings may also have more options for compensating for the lack of social support through friendship and peer group activities outside of the family.

Secondly, the results also show benefits from being born first, as compared to being born second, in a two-sibling family. This effect, too, is only observed for the poor and 
thus seems not to be of general character. While the first treatment estimates point to the siblings-as-support hypothesis, this is complicated by the estimates for the second treatment, showing that sibling benefits are enjoyed primarily by the sibling born first. Together, these findings do not support the idea that older siblings provide their younger siblings with resources. Instead, it seems more plausible to theorise siblings as resources in relation to which skills can be acquired - rather than as providers of support, or substitutes for other adult care-takers - and that these skills or resources may be valuable only in certain contexts. Should we then conceptualise the firstborn siblings, rather than the only children, as 'small emperors' and analyse this as a result from being the rulers of their secondborn 'servant' siblings? Not necessarily, since the effect is not observed for wealthy children. Among poor children, firstborns have advantages over their subsequently born siblings. But, these advantages do not seem to be related to the dilution of emotional, social, and economic family resources, as the analysis shows that it is clearly better to have siblings than to not have them for poor children. Competing for, or sharing, family resources - or learning to take responsibility for younger siblings - seem to produce gains for poor firstborns. These results suggest that sibling benefits are perhaps better conceptualised in terms of being a sibling, rather than having one. At least so for poor children. It may be the case that characteristics and behaviours are not fostered in younger siblings by their older siblings, but rather that firstborns gain maturity and responsibility from being the older sibling. This could contribute to better earnings outcomes for firstborns in the poor sample. A question of relevance for future research is whether these associations hold true for siblings of higher birth orders too. Is it better to be an only child, than to be born second?

While the firstborn advantage has commonly been explained by greater resource investments in the firstborn child (Conley and Glauber 2006; Pavan 2016), this argument is complicated by the findings presented here. The fact that the firstborn advantage is not observed for wealthy children supports the idea that this effect is in fact a dilution effect. However, if exclusivity in parental time and attention provides the firstborn with advantages, only children should perform better than siblings. In this analysis however, firstborn siblings actually compare favourably to children without siblings. This directs our attention not only to the dissolution, but to the acquirement, of resources by way of sibship. That no birth order effect is observed for the wealthy children indicates that their parents are so resourceful that siblings do not need to compete for resources, and that the younger siblings are compensated for their birth order disadvantage. It could also be the case that the skills provided by being the firstborn child is not of value for children growing up in affluence. It may be the case that different life courses need different strategies and thus different skills, or that social skills are measured in different ways for different groups of people. These results lend support to the conceptual model of adultification, that may inform empirical observations of the first born advantage. Recognizing that the potential positive effects of adultification is mediated by parental support gives us a more nuanced image of poor parents. Even when material resources are scarce, they may not be "inadequate", but able to make the child make sense of difficult circumstances and make use of the acquired abilities.

The findings in relation to the third treatment also show that the adverse effects of belonging to a large group of siblings are contingent on socioeconomic conditions. Having many siblings is clearly a disadvantage for poor children, but the results do not indicate any such corresponding effect among the wealthy. In other words, the analysis 
suggests that the adverse effects of large sibling constellations are indeed mediated by the economic resources of the parents, and it thus lends strong support for the resource dilution model. Dilution of resources may not be the only mechanism between a large sibling group and and lower earnings. One important difference between poor and rich families is the extent to which choice is a factor in determining family size. Having a child could be an unexpected and unplanned event and this could more commonly be the case for poor parents. The effect with regard to family size for poor children could also be explained not only by the reduction in resources due to each additional child, but from a reduction in the options they can exercise. Such impacts may be less likely to be experienced by families with greater wealth. Reductions in real choices may lead to conflicts, and also reductions in utilizing the available social and material resources, all of which could affect the child's path to lower earnings. It could also be the case that having more children substantially increases the likelihood that one will have some sort of serious problem in poor families. So, it is not just a problem of diluted financial resources, but all the additional challenges it brings for family functioning and child rearing. While important to investage further, such endogenous factors and mechanisms, are unfortunately out of reach for the data I employ here.

This analysis shows that relational aspects of the sibling configuration - whether one has a sibling or not, and the birth order of siblings - operate dependently of family resources. Economic affluence does seem to buffer children from the negative effects of being an only child, or being the younger sibling, or being part of a large sibling group. The results suggest that wealthy children are not affected by siblings, most likely because living standards remain high for these children even when additional siblings are introduced into the household, and that they are not in need of extra social support. That the effects of siblings are dependent on family resources underscores the importance of resources for understanding the mechanisms between siblings and child outcomes.

From a policy perspective, the most interesting result from this study is that one of the most well established links in family research - namely, the one between a large group of siblings and negative outcomes - cannot be observed for wealthy children, indicating that adverse sibling effects can be counteracted by investing in children and families. This study furthermore shows that sibling effects are not linear. For economically vulnerable children it is negative both to not have any siblings and to have a lot of them, while one sibling could provide gains.

This study is based on Swedish data, and the individuals in the data grew up during the golden age of the Swedish welfare state with extensive economic support to families, public day care, and an educational system free of charge even for higher education. It is thus not an entirely straightforward process to relate the results of this study to other contexts. It is not unreasonable to assume that sibling effects due to economic strain or affluence might be even more pronounced in contexts lacking the structures of support available to the population analysed here. The results show the usefulness of analysing outcomes among different groups for furthering the understanding of the relationship between economic contexts and family relations. Disentangling the ways in which mechanisms intersect is of critical importance for future research. Analysing children at exceptional risk - as well as those of exceptional well-being - can help us understand how familial and economic mechanisms affect the lives of children. There is still much to be learned about the context-specificity of sibling effects. If a sibling provides poor children with substantial benefits, it is of 
crucial importance to learn more about the mechanisms through which these benefits are produced and acquired, so that they can be transferred also to children without siblings or those of higher birth order.

\section{Appendix}

Table 3 Descriptive statistics and mean difference in the covariates before and after matching. Only child (poor children)

\begin{tabular}{lrrrrr}
\hline & \multicolumn{2}{l}{ Before matching } & & \multicolumn{2}{l}{ Mean difference } \\
\cline { 2 - 3 } \cline { 5 - 6 } & Treated & Control & & Before & After \\
\hline Female gender & 0,48 & 0,49 & & $-0,01$ & $-0,02$ \\
Mother year of birth & 1947,9 & 1949,9 & & $-2,00$ & 0,00 \\
Father year of birth & 1944,8 & 1947,1 & & $-2,30$ & 0,10 \\
Mother earnings 1975 & 2513 & 2872 & & -359 & -19 \\
Father earnings 1975 & 4987 & 5038 & & 60 & 85 \\
Mother non-western origin & 0,01 & 0,00 & & 0,01 & 0,00 \\
Mother tertiary education & 0,01 & 0,01 & & 0,00 & 0,00 \\
Father non-western origin & 0,01 & 0,01 & & 0,00 & 0,00 \\
Father tertiary education & 0,02 & 0,01 & & $-0,03$ & 0,00 \\
\hline
\end{tabular}

Earnings indicated in US dollars, rounded off to the nearest dollar

Table 4 Descriptive statistics and mean difference in the covariates before and after matching. Only child (wealthy children)

\begin{tabular}{lllll}
\hline Covariate & $\begin{array}{l}\text { Before matching } \\
\text { Treated }\end{array}$ & $\begin{array}{l}\text { Mean difference } \\
\text { Control }\end{array}$ & Before & After \\
\hline Female gender & 0,50 & 0,49 & 0,01 & 0,02 \\
Mother year of birth & 1942,6 & 1944,9 & $-2,30$ & 0,01 \\
Father year of birth & 1940,3 & 1942,9 & $-2,60$ & 0,00 \\
Mother earnings 1975 & 4711 & 4678 & 33 & 51 \\
Father earnings 1975 & 9066 & 9147 & -85 & -45 \\
Mother non-western origin & 0,01 & 0,01 & 0,00 & 0,00 \\
Mother tertiary education & 0,22 & 0,30 & $-0,08$ & 0,01 \\
Father non-western origin & 0,02 & 0,02 & 0,00 & 0,00 \\
Father tertiary education & 0,26 & 0,32 & $-0,08$ & 0,01 \\
\hline
\end{tabular}

Earnings indicated in US dollars, rounded off to the nearest dollar 
Table 5 Descriptive statistics and mean difference in the covariates before and after matching. Firstborn child (poor children)

\begin{tabular}{|c|c|c|c|c|}
\hline \multirow[t]{2}{*}{ Covariate } & \multicolumn{2}{|c|}{ Before matching } & \multicolumn{2}{|c|}{ Mean difference } \\
\hline & Treated & Control & Before & After \\
\hline Female gender & 0,49 & 0,49 & 0,00 & 0,00 \\
\hline Mother year of birth & 1949,9 & 1946,90 & 3,00 & 0,10 \\
\hline Father year of birth & 1947,1 & 1944,00 & 3,10 & 0,20 \\
\hline Mother earnings 1975 & 2869 & 2026 & 843 & 31 \\
\hline Father earnings 1975 & 5031 & 5027 & 4 & 13 \\
\hline Mother non-western origin & 0,00 & 0,00 & 0,00 & 0,00 \\
\hline Mother tertiary education & 0,01 & 0,01 & 0,00 & 0,00 \\
\hline Father non-western origin & 0,01 & 0,01 & 0,00 & 0,00 \\
\hline Father tertiary education & 0,01 & 0,02 & 0,00 & 0,00 \\
\hline
\end{tabular}

Earnings indicated in US dollars, rounded off to the nearest dollar

Table 6 Descriptive statistics and mean difference in the covariates before and after matching. Firstborn child (wealthy children)

\begin{tabular}{|c|c|c|c|c|}
\hline \multirow[t]{2}{*}{ Covariate } & \multicolumn{2}{|c|}{ Before matching } & \multicolumn{2}{|c|}{ Mean difference } \\
\hline & Treated & Control & Before & After \\
\hline Female gender & 0,49 & 0,48 & 0,01 & 0,01 \\
\hline Mother year of birth & 1944,9 & 1942,30 & 2,60 & 0,00 \\
\hline Father year of birth & 1942,9 & 1940,10 & 2,80 & 0,00 \\
\hline Mother earnings 1975 & 4678 & 4130 & 546 & 13 \\
\hline Father earnings 1975 & 9148 & 10,003 & -855 & 6 \\
\hline Mother non-western origin & 0,01 & 0,02 & $-0,01$ & $-0,01$ \\
\hline Mother tertiary education & 0,30 & 0,30 & $-0,01$ & 0,02 \\
\hline Father non-western origin & 0,02 & 0,02 & $-0,01$ & $-0,01$ \\
\hline Father tertiary education & 0,32 & 0,35 & $-0,03$ & 0,01 \\
\hline
\end{tabular}

Earnings indicated in US dollars, rounded off to the nearest dollar

Table 7 Descriptive statistics and mean difference in the covariates before and after matching. Large sibling group (poor children)

\begin{tabular}{lrrrrr}
\hline Covariate & \multicolumn{2}{l}{ Before matching } & & \multicolumn{2}{l}{ Mean difference } \\
\cline { 2 - 3 } & Treated & Control & & Before & After \\
\hline Gender women & 0,51 & 0,49 & & 0,03 & 0,00 \\
Mother year of birth & 1951,5 & 1950,20 & & 1,30 & 0,00
\end{tabular}


Table 7 (continued)

\begin{tabular}{|c|c|c|c|c|}
\hline \multirow[t]{2}{*}{ Covariate } & \multicolumn{2}{|c|}{ Before matching } & \multicolumn{2}{|c|}{ Mean difference } \\
\hline & Treated & Control & Before & After \\
\hline Father year of birth & 1948,9 & 1947,50 & 1,40 & 0,00 \\
\hline Mother earnings 1975 & 3426 & 2968 & 46 & -6 \\
\hline Father earnings 1975 & 4478 & 4906 & 428 & 41 \\
\hline Mother non-western origin & 0,00 & 0,00 & 0,00 & 0,00 \\
\hline Mother tertiary education & 0,00 & 0,00 & 0,00 & 0,00 \\
\hline Father non-western origin & 0,01 & 0,01 & 0,00 & 0,00 \\
\hline Father tertiary education & 0,01 & 0,01 & 0,00 & 0,00 \\
\hline
\end{tabular}

Earnings indicated in US dollars, rounded off to the nearest dollar

Table 8 Descriptive statistics and mean difference in the covariates before and after matching. Large sibling group (wealthy children)

\begin{tabular}{|c|c|c|c|c|}
\hline \multirow[t]{2}{*}{ Covariate } & \multicolumn{2}{|c|}{ Before matching } & \multicolumn{2}{|c|}{ Mean difference } \\
\hline & Treated & Control & Before & After \\
\hline Female gender & 0,46 & 0,48 & $-0,02$ & $-0,04$ \\
\hline Mother year of birth & 1946,3 & 1945,2 & 1,10 & 0,10 \\
\hline Father year of birth & 1944,4 & 1943,2 & 1,20 & 0,00 \\
\hline Mother earnings 1975 & 4642 & 4604 & 36 & 306 \\
\hline Father earnings 1975 & 9910 & 9250 & 655 & -137 \\
\hline Mother non-western origin & 0,01 & 0,01 & 0,00 & 0,00 \\
\hline Mother tertiary education & 0,30 & 0,30 & 0,00 & $-0,01$ \\
\hline Father non-western origin & 0,02 & 0,01 & 0,00 & 0,02 \\
\hline Father tertiary education & 0,32 & 0,32 & 0,00 & $-0,01$ \\
\hline
\end{tabular}

Earnings indicated in US dollars, rounded off to the nearest dollar

Table 9 Results logistic regressions (poor children)

\begin{tabular}{|c|c|c|c|c|c|c|}
\hline \multirow[b]{3}{*}{ Intercept } & \multicolumn{6}{|l|}{ Odds ratio } \\
\hline & \multicolumn{2}{|l|}{ only child } & \multicolumn{2}{|l|}{ firstborn child } & \multicolumn{2}{|c|}{ large sibling group } \\
\hline & $1,16 \mathrm{E}-104$ & $* * *$ & $2,90 \mathrm{E}+181$ & $* * *$ & 0,00 & $* * *$ \\
\hline Female gender & 1,03 & & 1,02 & & 1,10 & $*$ \\
\hline Mother year of birth & 1,08 & $* * *$ & 0,85 & $* * *$ & 1,12 & $* * *$ \\
\hline Father year of birth & 1,04 & $* * *$ & 0,95 & $* * *$ & 1,06 & $* * *$ \\
\hline
\end{tabular}


Table 9 (continued)

\section{Odds ratio}

\begin{tabular}{|c|c|c|c|c|c|c|}
\hline \multirow{2}{*}{$\begin{array}{l}\text { only child } \\
\text { Mother earnings } 1975\end{array}$} & \multirow[b]{2}{*}{1,00} & \multicolumn{2}{|c|}{ firstborn child } & \multicolumn{2}{|c|}{$\begin{array}{l}\text { large sibling } \\
\text { group }\end{array}$} & \multirow[b]{2}{*}{$* * *$} \\
\hline & & $* * *$ & 1,00 & $* * *$ & 1,00 & \\
\hline Father earnings 1975 & 1,00 & & 1,00 & & 1,00 & $* * *$ \\
\hline Mother non-western origin & 0,42 & . & 0,84 & & 1,37 & \\
\hline Father non-western origin & 1,49 & & 1,22 & & 1,70 & . \\
\hline Mother tertiary education & 0,98 & & 0,81 & & 1,02 & \\
\hline Father tertiary education & 1,48 & . & 0,42 & $* * *$ & 1,55 & . \\
\hline
\end{tabular}

Significance levels: $0=$ “***’ $0.001=$ “**’ $0.01=$ “*’ $0.05=$ ' $0.1=$ “

Table 10 Results logistic regressions (wealthy children)

\begin{tabular}{|c|c|c|c|c|c|c|}
\hline & \multicolumn{6}{|l|}{ Odds ratio } \\
\hline & \multicolumn{2}{|l|}{ Only child } & \multicolumn{3}{|l|}{ Firstborn child } & \multirow{2}{*}{$\frac{\text { Large sibling group }}{* * *}$} \\
\hline Intercept & $8,24 \mathrm{E}-65$ & $* * *$ & $3,83 \mathrm{E}+234$ & $* * *$ & $1,27 \mathrm{E}-177$ & \\
\hline Female gender & 0,92 & & 0,96 & & 0,90 & \\
\hline Mother year of birth & 1,04 & $* * *$ & 0,82 & $* * *$ & 1,13 & $* * *$ \\
\hline Father year of birth & 1,03 & $* * *$ & 0,92 & $* * *$ & 1,09 & $* * *$ \\
\hline Mother income 1975 & 1,00 & & 1,00 & $* * *$ & 1,00 & $\cdot$ \\
\hline Father income 1975 & 1,00 & $* * *$ & 1,00 & $* * *$ & 1,00 & $* * *$ \\
\hline Mother non-western origin & 1,56 & & 1,30 & & 0,62 & \\
\hline Father non-western origin & 1,16 & & 1,45 & $*$ & 1,52 & \\
\hline Mother tertiary education & 1,64 & $* * *$ & 0,96 & & 1,35 & $* * *$ \\
\hline Father tertiary education & 1,25 & $* * *$ & 0,86 & $* * *$ & 1,24 & $*$ \\
\hline
\end{tabular}

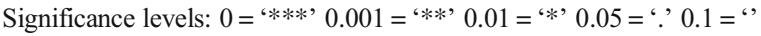

Table 11 Sensitivity test. estimates are P-value after changes in Gamma $(\Gamma)$ (poor children)

\begin{tabular}{llll}
\hline$\Gamma$ & Only child & Firstborn child & Large sibling group \\
\hline 1.0 & 0,00 & 0,00 & 0,00 \\
1.1 & 0,00 & 0,00 & 0,00 \\
1.2 & 0,62 & 1,00 & 0,00 \\
1.3 & 1,00 & 1,00 & 0,99 \\
1.4 & 1,00 & 1,00 & 1,00 \\
1.5 & 1,00 & 1,00 & 1,00 \\
\hline
\end{tabular}


Propensity Scores

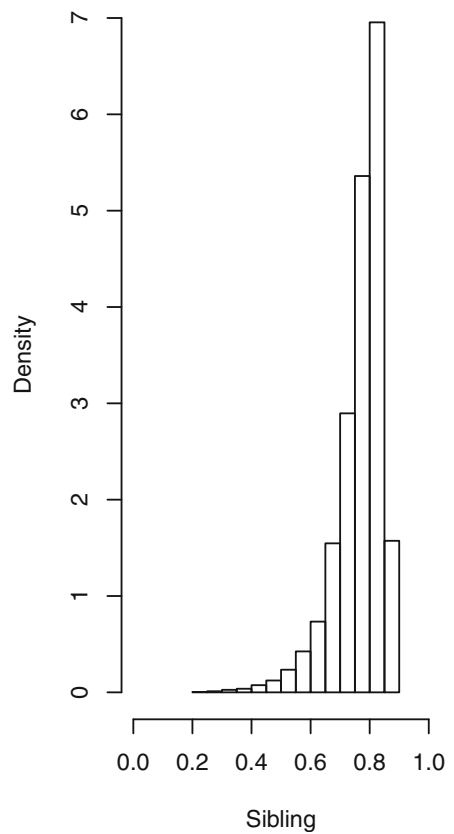

Propensity Scores

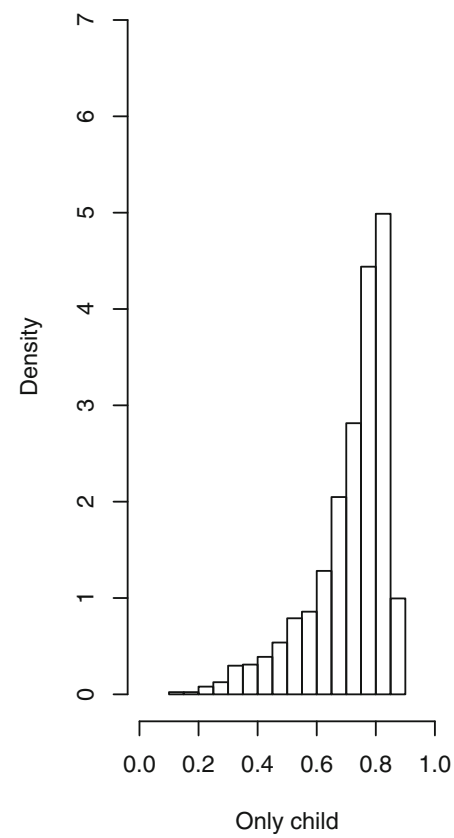

Fig. 1 Histograms. Distribution propensity scores. Only child/Sibling. Poor children

Propensity Scores

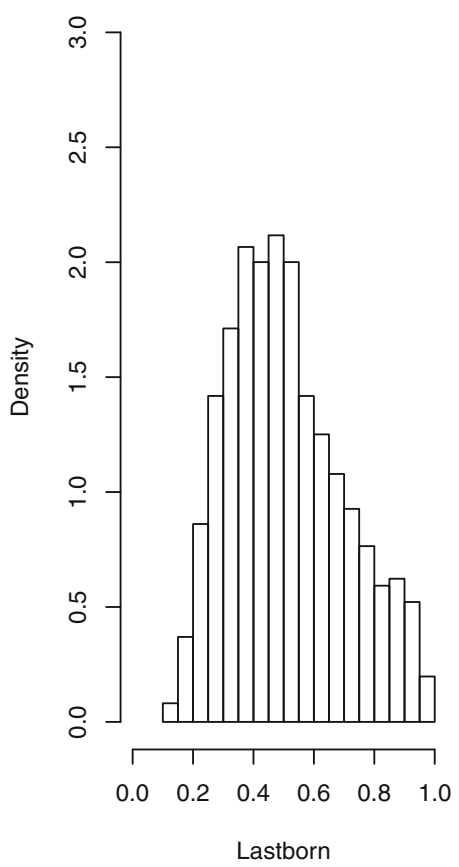

Propensity Scores

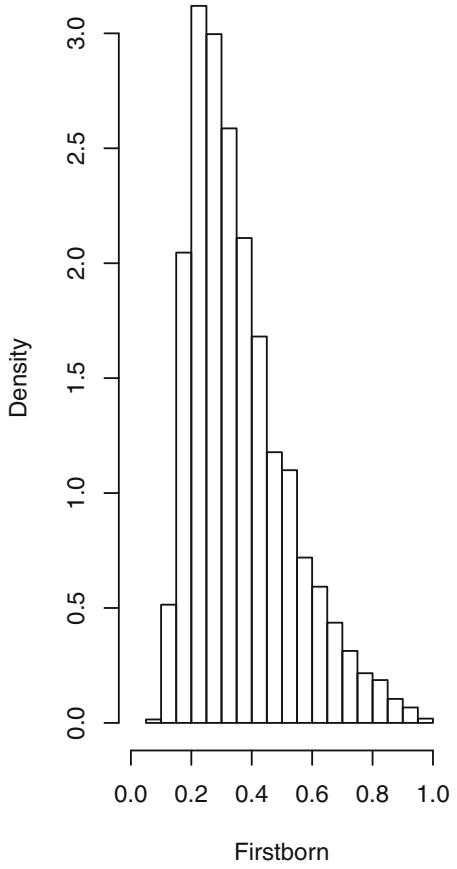

Fig. 2 Histograms. Distribution propensity scores. Firstborn/Lastborn. Poor children 
Propensity Scores

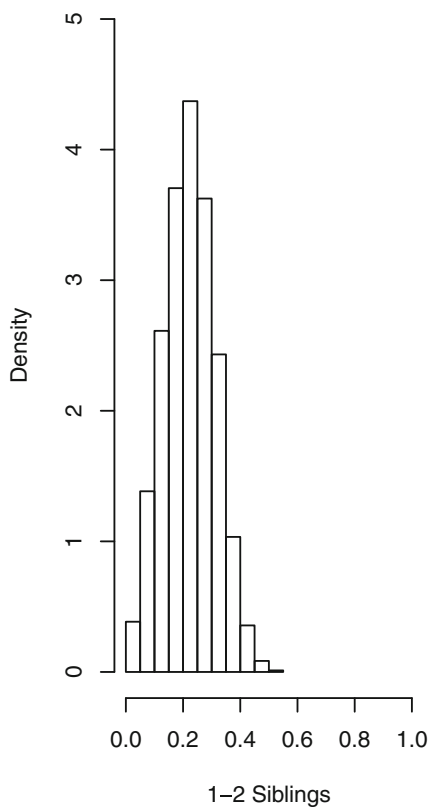

Propensity Scores

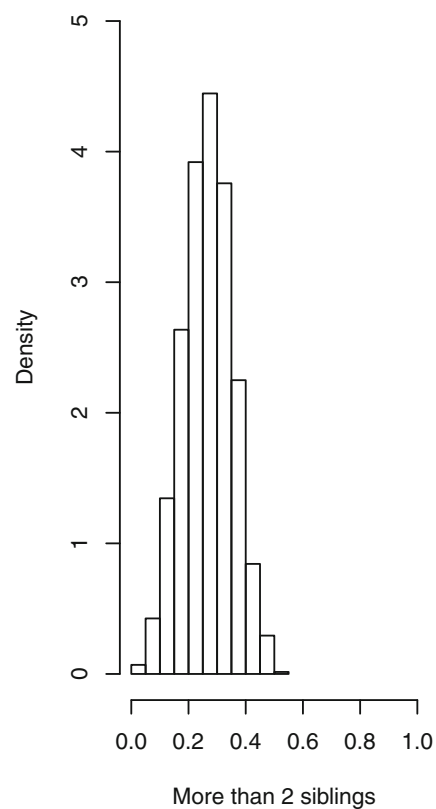

Fig. 3 Histograms. Distribution propensity scores. More than 2 siblings/1-2 siblings. Poor children

Propensity Scores

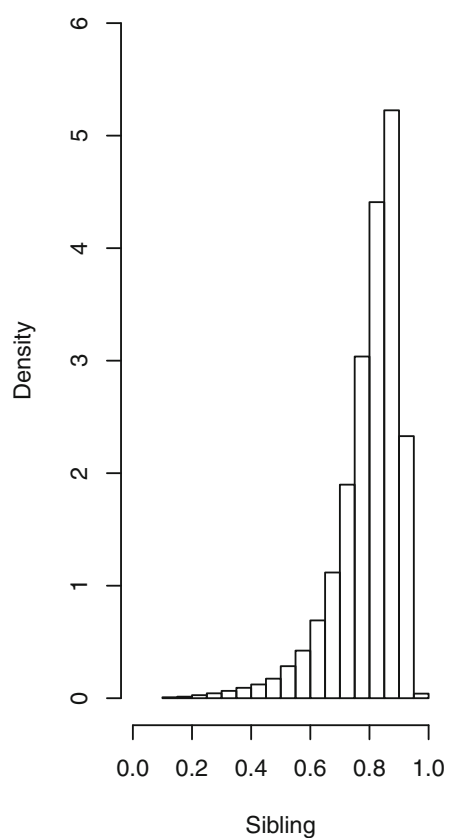

Propensity Scores

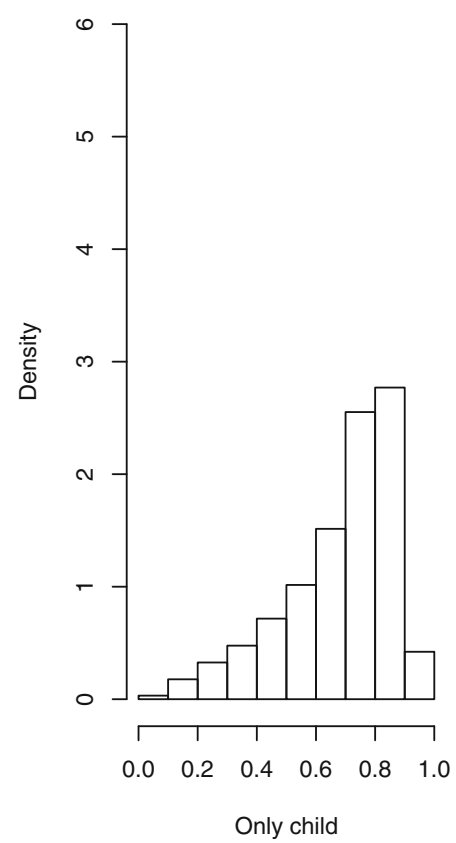

Fig. 4 Histograms. Distribution propensity scores. Only child/Sibling. Rich children 
Propensity Scores

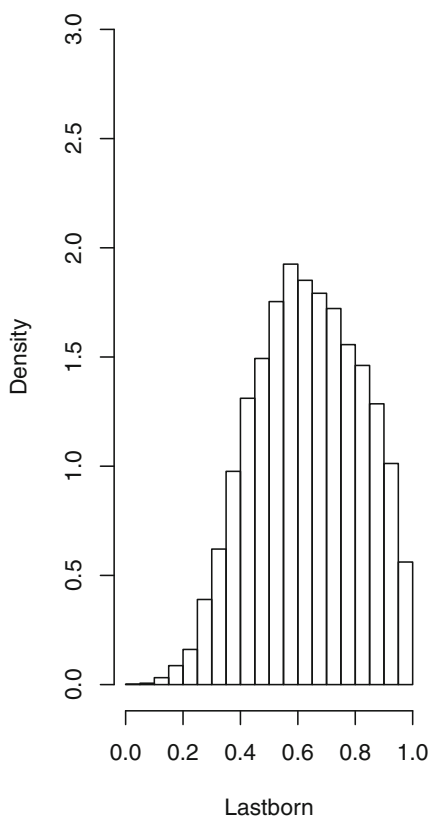

Propensity Scores

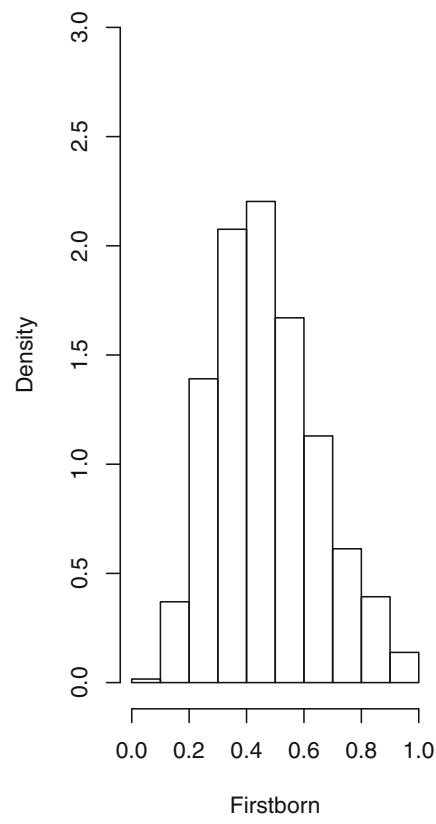

Fig. 5 Histograms. Distribution propensity scores. Firstborn/Lastborn. Rich children

Propensity Scores

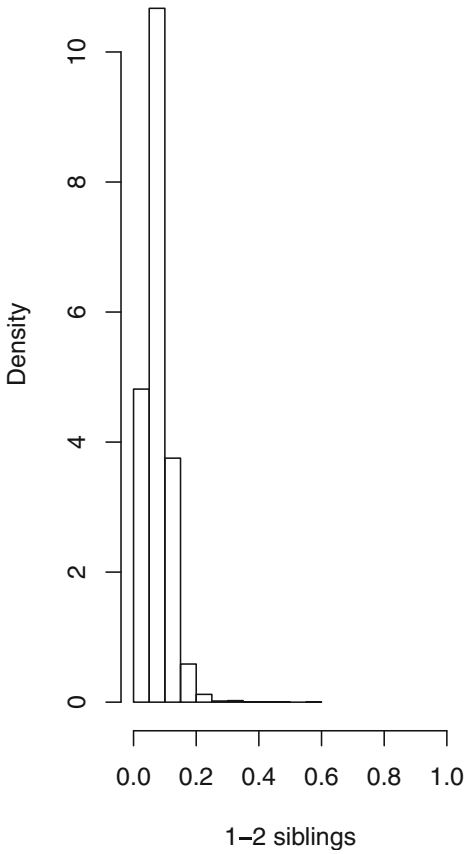

Propensity Scores

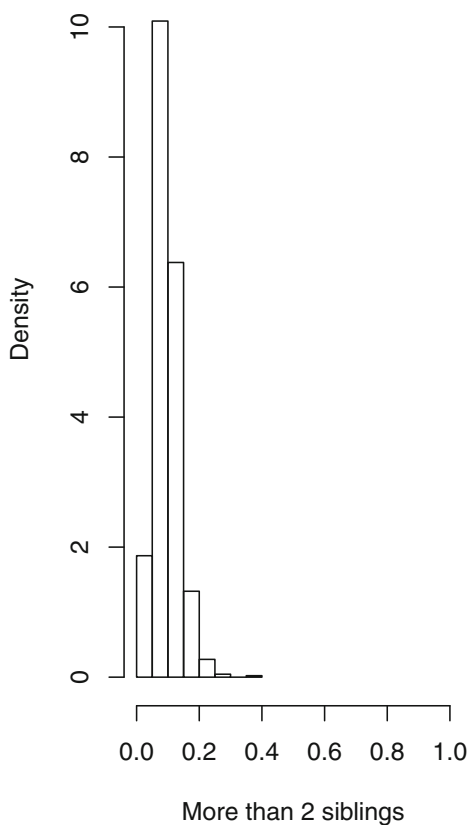

Fig. 6 Histograms. Distribution propensity scores. More than 2 siblings/1-2 siblings. Rich children 
Open Access This article is distributed under the terms of the Creative Commons Attribution 4.0 International License (http://creativecommons.org/licenses/by/4.0/), which permits unrestricted use, distribution, and reproduction in any medium, provided you give appropriate credit to the original author(s) and the source, provide a link to the Creative Commons license, and indicate if changes were made.

\section{References}

Abadie, A., \& Imbens, G. W. (2006). Large sample properties of matching estimators for average treatment effects. Econometrica, 74(1), 235-267.

Aizer, A., Stroud, L., \& Buka, S. (2016). Maternal stress and child outcomes: Evidence from siblings. Journal of Human Resources, 51, 523-555.

Åslund, O., \& Grönqvist, H. (2010). Family size and child outcomes: Is there really no trade-off? Labour Economics, 17(1), 130-139.

Baydar, N., Greek, A., \& Brooks-Gunn, J. (1997). A longitudinal study of the effects of the birth of a sibling during the first 6 years of life. Journal of Marriage and the Family, 59(4), 939-956.

Björklund, A., Jäntti, M., \& Lindquist, M. J. (2009). Family background and earnings during the rise of the welfare state: Brother correlations in earnings for Swedish men born 1932-1968. Journal of Public Economics, 93(5), 671-680.

Blake, J. (1981). Family size and the quality of children. Demography, 18(4), 421-442.

Blau, P. M., \& Duncan, O. D. (1967). The American occupational structure. New York: Wiley.

Brooks-Gunn, J., \& Duncan, G. J. (1997). The effects of poverty on children. The Future of Children, 7(2), $55-71$.

Burton, L. (2007). Childhood Adultification in economically disadvantaged families: A conceptual model. Family Relations, 56(4), 329-345.

Cameron, L., Erkal, N., Gangadharan, L., \& Meng, X. (2013). Little emperors: Behavioral impacts of China's one-child policy. Science, 339(6122), 953-957.

Cohen, S., \& Wills, T. A. (1985). Stress, social support, and the buffering hypothesis. Psychological Bulletin, 98(2), 310-357.

Coleman, J. S. (1988). Social Capital in the Creation of human capital. The American Journal of Sociology, 94, 95-120.

Conger, R. D., Ge, X., Elder, G. H., Lorenz, F. O., \& Simons, R. L. (1994). Economic stress, coercive family process, and developmental problems of adolescents. Child Development, 65(2), 541-561.

Conger, K. J., Stocker, C., \& McGuire, S. (2009). Siblings as agents of socialization. In L. Kramer \& K. Conger (Eds.), Sibling socialization: The effects of stressful life events and experiences. New directions for child and adolescent development (pp. 45-60). San Francisco: Jossey-Bass.

Conley, D. (2001). Capital for college: Parental assets and postsecondary schooling. Sociology of Education, 74(1), 59-72.

Conley, D., \& Glauber, R. (2006). Parental educational investment and children's academic risk estimates of the impact of sibship size and birth order from exogenous variation in fertility. Journal of Human Resources, 41(4), 722-737.

Conley, D., \& Glauber, R. (2008). All in the family?: Family composition, resources, and sibling similarity in socioeconomic status. Research in Social Stratification and Mobility, 26(4), 297-306.

Crowell, T., \& Hsieh, D. (1995). Little emperors: Is China's one-child policy creating a Society of Brats? Asiaweek, 21(48), 44-50.

Dahl, G. B., \& Lochner, L. (2012). The impact of family income on child achievement: Evidence from the earned income tax credit. The American Economic Review, 102(5), 1927-1956.

De Haan, M., Plug, E., \& Rosero, J. (2014). Birth order and human capital development evidence from Ecuador. Journal of Human Resources, 49(2), 359-392.

Downey, D. B. (1995). When bigger is not better: Family size, parental resources, and children's educational performance. American Sociological Review, 60(5), 746-761.

Downey, D. B. (2001). Number of siblings and intellectual development: The resource dilution explanation. American Psychologist, 56(6-7), 497-504.

Downey, D. B., \& Condron, D. J. (2004). Playing well with others in kindergarten: The benefit of siblings at home. Journal of Marriage and Family, 66(2), 333-350. 
Downey, D. B., Condron, D. J., \& Yucel, D. (2015). Number of siblings and social skills revisited among American fifth graders. Journal of Family Issues, 36(2), 273-296.

Emery, R. E., \& Laumann-Billings, L. (1998). An overview of the nature, causes, and consequences of abusive family relationships: Toward differentiating maltreatment and violence. American Psychologist, 53(2), 121-135.

Evans, G. W. (2004). The environment of childhood poverty. American Psychologist, 59(2), 77-92.

Ferguson, K. M. (2006). Social capital and children's wellbeing: A critical synthesis of the international social capital literature. International Journal of Social Welfare, 15(1), 2-18.

Gass, K., Jenkins, J., \& Dunn, J. (2007). Are sibling relationships protective? A longitudinal study. Journal of Child Psychology and Psychiatry, 48(2), 167-175.

Guo, G., \& Harris, K. M. (2000). The mechanisms mediating the effects of poverty on children's intellectual development. Demography, 37(4), 431-447.

Herrick, M. A., \& Piccus, W. (2005). Sibling connections: The importance of nurturing sibling bonds in the foster care system. Children and Youth Services Review, 27(7), 845-861.

Holland, P. W. (1986). Statistics and causal inference. Journal of the American Statistical Association, 81(396), 945-960.

Imbens, G. W. (2015). Matching methods in practice: Three examples. Journal of Human Resources, 50(2), 373-419.

Israel, G. D., Beaulieu, L. J., \& Hartless, G. (2001). The influence of family and community social capital on educational achievement. Rural Sociology, 66(1), 43-68.

Jæger, M. M. (2009). Sibship size and educational attainment. A joint test of the confluence model and the resource dilution hypothesis. Research in Social Stratification and Mobility, 27(1), 1-12.

Kantarevic, J., \& Mechoulan, S. (2006). Birth order, educational attainment, and earnings an investigation using the PSID. Journal of Human Resources, 41(4), 755-777.

Keele, L. (2014). rbounds: Perform Rosenbaum bounds sensitivity tests for matched and unmatched data. R package version 2.1. https://CRAN.R-project.org/package=rbounds

Kempton, T., Armistead, L., Wierson, M., \& Forehand, R. (1991). Presence of a sibling as a potential buffer following parental divorce - an examination of young adolescents. Journal of Clinical Child and Adolescent Psychology, 20(4), 434-438.

Lampi, E., \& Nordblom, K. (2012). Nature and nurture: The relation between number of siblings and earnings. Applied Economics Letters, 19(8), 759-762.

Lau, M., \& Li, W. (2011). The extent of family and school social capital promoting positive subjective wellbeing among primary school children in Shenzhen, China. Children and Youth Services Review, 33(9), $1573-1582$.

Leventhal, T., \& Brooks-Gunn, J. (2000). The neighborhoods they live in: The effects of neighborhood residence on child and adolescent outcomes. Psychological Bulletin, 126(2), 309-337.

Lu, Y. (2009). Sibship size and education in South Africa: Black-white variations. Research in Social Stratification and Mobility, 27(2), 110-125.

Lugo-Gil, J., \& Tamis-LeMonda, C. S. (2008). Family resources and parenting quality: Links to children's cognitive development across the first 3 years. Child Development, 79(4), 1065-1085.

Luthar, S. S. (2003). The culture of affluence: Psychological costs of material wealth. Child Development, 74(6), 1581-1593.

Luthar, S. S., \& Becker, B. E. (2002). Privileged but pressured? A study of affluent youth. Child Development, 73(5), 1593-1610.

Luthar, S. S., \& Latendresse, S. J. (2005). Children of the affluent challenges to well-being. Current Directions in Psychological Science, 14(1), 49-53.

Luthar, S. S., \& Sexton, C. C. (2004). The high price of affluence. Advances in Child Development and Behavior, 32, 125-162.

Magnuson, K. A., \& Duncan, G. J. (2002). Parents in poverty. In M. H. Bornstein (Ed.), Handbook of parenting (Vol. 4. Social Conditions and Applied Parenting, pp. 95-121). New Jersey: Lawrence Erlbaum Associated Publishers.

Marmot, M. G., \& Wilkinson, R. G. (Eds.). (2006). Social determinants of health. Oxford: Oxford University Press.

Mayer, S. E. (1997). What money can't buy: Family income and children's life chances. Cambridge: Harvard University Press.

Milevsky, A. (2005). Compensatory patterns of sibling support in emerging adulthood: Variations in loneliness, self-esteem, depression and life satisfaction. Journal of Social and Personal Relationships, 22(6), $743-755$. 
Parcel, T. L., Dufur, M. J., \& Cornell Zito, R. (2010). Capital at home and at school: A review and synthesis. Journal of Marriage and Family, 72(4), 828-846.

Pavan, R. (2016). On the production of skills and the birth order effect. Journal of Human Resources, 51(3), 699-726.

Phillips, R. (1999). Intervention with siblings of children with developmental disabilities from economically disadvantaged families. Families in Society: The Journal of Contemporary Social Services, 80(6), 569577.

Ponczek, V., \& Souza, A. P. (2012). New evidence of the causal effect of family size on child quality in a developing country. Journal of Human Resources, 47(1), 64-106.

Powell, B., \& Steelman, L. C. (1990). Beyond sibship size: Sibling density, sex composition, and educational outcomes. Social Forces, 69(1), 181-206.

Putnam, R. (2000). Bowling alone, the collapse and revival of civic America. New York: Simon \& Schuster.

R Core Team (2013). R: A language and environment for statistical computing. R Foundation for Statistical Computing, Vienna, Austria., URL http://www.R-project.org/.

Ridge, T. (2002). Childhood poverty and social exclusion: From a Child's perspective. Bristol: Policy Press.

Ridge, T. (2011). The everyday costs of poverty in childhood: A review of qualitative research exploring the lives and experiences of low-income children in the UK. Children \& Society, 25(1), 73-84.

Rosenbaum, P. R. (2004). Design sensitivity in observational studies. Biometrika, 91(1), 153-164.

Rosenbaum, P. R., \& Rubin, D. B. (1983). The central role of the propensity score in observational studies for causal effects. Biometrika, 70(1), 41-55.

Roy, K., Messina, L., Smith, J., \& Waters, D. (2014). Growing up as "man of the house": Adultification and transition into adulthood for young men in economically disadvantaged families. In K. Roy \& N. Jones (Eds.), Pathways to adulthood for disconnected young men in low-income communities. New Directions in Child and Adolescent Development, 143, 55-72.

Rubin, D. B. (1974). Estimating causal effects of treatments in randomized and nonrandomized studies. Journal of Educational Psychology, 66(5), 688-701.

Sandefur, G. D., Meier, A. M., \& Campbell, M. E. (2006). Family resources, social capital, and college attendance. Social Science Research, 35(2), 1573-1582.

Sandler, I. N. (1980). Social support resources, stress, and maladjustment of poor children. American Journal of Community Psychology, 8(1), 41-52.

Seccombe, K. (2000). Families in poverty in the 1990s: Trends, causes, consequences, and lessons learned. Journal of Marriage and Family, 62(4), 1094-1113.

Sekhon, J. S. (2011). Multivariate and propensity score matching software with automated balance optimization: The matching package for R. Journal of Statistical Software, 42(7), 1-52.

Slack, K. S., Holl, J. L., McDaniel, M., Yoo, J., \& Bolger, K. (2004). Understanding the risks of child neglect: An exploration of poverty and parenting characteristics. Child Maltreatment, 9(4), 395-408.

Steelman, L. C., Powell, B., Werum, R., \& Carter, S. (2002). Reconsidering the effects of sibling configuration: Recent advances and challenges. Annual Review of Sociology, 28, 243-269.

Wang, Y., \& Fong, V. L. (2009). Little emperors and the 4:2:1 generation: China's singletons. Child \& Adolescent Psychiatry, 48(12), 1137-1139.

White, L., \& Rogers, S. J. (2000). Economic circumstances and family outcomes: A review of the 1990s. Journal of Marriage and Family, 62(4), 1035-1051.

Yucel, D., \& Downey, D. B. (2015). When quality trumps quantity: Siblings and the development of peer relationships. Child Indicators Research, 8(4), 845-865.

Yucel, D., \& Yuan, A. V. (2015). Do siblings matter? The effect of siblings on socio-emotional development and educational aspirations among early adolescents. Child Indicators Research, 8(4), 671-697.

Zajonc, R. B. (1976). Family configuration and intelligence: Variations in scholastic aptitude scores parallel trends in family size and the spacing of children. Science, 149(3681), 269-274.

Zajonc, R. B. (2001). The family dynamics of intellectual development. American Psychologist, 56(6-7), 490-496.

Zajonc, R. B., \& Markus, G. B. (1975). Birth order and intellectual development. Psychological Review, 82(1), 74-88.

Zajonc, R. B., \& Sulloway, F. J. (2007). The confluence model: Birth order as a within-family or betweenfamily dynamic? Personality and Social Psychology Bulletin, 33(9), 1187-1194. 